\title{
Assigning fates in telemetry studies using hidden Markov models: an application to deepwater groupers released with descender devices
}

Running head: Hidden Markov models can assist fate assignment in survival studies

\section{Brendan J. Runde', Théo Michelot ${ }^{2}$, Nathan M. Bacheler ${ }^{3}$, Kyle W. Shertzer ${ }^{3}$, and Jeffrey A. Buckel $^{1}$}

${ }^{1}$ Center for Marine Sciences and Technology, Department of Applied Ecology, North Carolina State University, 303 College Circle, Morehead City, North Carolina 28557, USA.

${ }^{2}$ School of Mathematics and Statistics, Centre for Research into Ecological and Environmental Modelling, University of St Andrews, St Andrews, UK.

${ }^{3}$ Southeast Fisheries Science Center, National Marine Fisheries Service, Beaufort, North Carolina 28516, USA.

\section{Abstract}

Fate assignment is crucial to the results of survival studies, particularly those that utilize acoustic tagging. Most current methodologies are at least partially subjective, thus having a means of objectively assigning fates would improve precision, accuracy, and utility of such studies. We released 57 acoustically tagged deepwater groupers of six species off North Carolina, USA, via surface release and recompressed release with descender devices. We applied a three-state hidden Markov model (HMM) in a novel way, to identify movement patterns associated not only to the behavior of live groupers, but also to the behavior of their predators or scavengers. We assigned fates using two approaches that differed in their reliance on HMMs. When HMMs were the predominant source of fate assignment, we estimated survival of 40 deepwater groupers released with descender devices at the continental shelf break (66-120 $\mathrm{m}$ depth) to be 0.46 ( $95 \%$ confidence interval 0.33 , 0.65). When a combination of HMMs and prior information was utilized, we estimated survival of the same 40 groupers to be $0.61(0.47,0.80)$. Both estimates represent a substantial improvement over survival for surface releases ( zero). Furthermore, HMMs estimated zero survival for an additional five descended groupers at a wreck site in $240 \mathrm{~m}$ depth, though one analysis using prior information

This article has been accepted for publication and undergone full peer review but has not been through the copyediting, typesetting, pagination and proofreading process, which may lead to differences between this version and the Version of Record. Please cite this article as doi: $10.1002 / \mathrm{nafm} .10504$

This article is protected by copyright. All rights reserved 
suggests survival may be possible in that depth. These estimates were aided by the objectivity of HMMs and we recommend future survival studies involving acoustic tagging employ similar methodologies. The improved survival of groupers after descending is an important finding for management, as this taxon contains several species of impaired stock status or fishery status.

This article is protected by copyright. All rights reserved 
DR. NATHAN BACHELER (Orcid ID : 0000-0003-1955-6044)

Article type : Article

Corresponding author mail id:- bjrunde@ncsu.edu

Assigning fates in telemetry studies using hidden Markov models: an application to deepwater groupers released with descender devices

Brendan J. Runde

Théo Michelot

Nathan M. Bacheler

Kyle W. Shertzer

Jeffrey A. Buckel

\begin{abstract}
Fate assignment is crucial to the results of survival studies, particularly those that utilize acoustic tagging. Most current methodologies are at least partially subjective, thus having a means of objectively assigning fates would improve precision, accuracy, and utility of such studies. We released 57 acoustically tagged deepwater groupers of six species off North Carolina, USA, via surface release and recompressed release with descender devices. We applied a three-state hidden Markov model (HMM) in a novel way, to distinguish movement patterns between alive and dead fish (which might have been eaten by predators). We assigned fates using two
\end{abstract}

This article is protected by copyright. All rights reserved 
approaches that differed in their reliance on HMMs. When HMMs were the predominant source of fate assignment, we estimated survival of 40 deepwater groupers released with descender devices at the continental shelf break (66-120 m depth) to be 0.46 (95\% confidence interval 0.33 , 0.65). When a combination of HMMs and prior information was utilized, we estimated survival of the same 40 groupers to be $0.61(0.47,0.80)$. Both estimates represent a substantial improvement over survival of surface released grouper ( zero). Furthermore, HMMs estimated zero survival for an additional five descended groupers at a wreck site in $240 \mathrm{~m}$ depth, though one analysis using prior information suggests survival may be possible in that depth. These estimates were aided by the objectivity of HMMs and we recommend future survival studies involving acoustic tagging employ similar methodologies. The improved survival of groupers after descending is an important finding for management, as this taxon contains several species of impaired stock status or fishery status.

\section{Introduction}

The use and utility of electronic tags in ecology has grown in recent years as such devices have become smaller, cheaper, and more advanced (Kays et al. 2015; Crossin et al. 2017). The incorporation of miniaturized sensors into tags enables scientists to collect a greater variety of information about tagged animals and offers flexibility in study design and objectives (Wilson et al. 2015). For example, sensors for metrics such as temperature (Gorsky et al. 2012), pH (Halfyard et al. 2017), light (Seitz et al. 2019), depth (Bohaboy et al. 2019), and acceleration (Curtis et al. 2015) can provide much insight into biology, movement, and survival (Runde et al. 2018). However, the pace of these technological advances has often outstripped the development of methods for the analysis of the data they produce. Novel techniques for processing the vast amounts and diverse types of data created by modern telemetry studies are required to maximize the benefits of electronic tagging.

One modern application of electronic tagging is the use of acoustic transmitters to obtain information about post-release (or discard) survival of fishes (e.g., Brill et al. 2002). Studies intending to estimate fish discard survival have become more frequent in recent years as this value has become more important to stock assessments (Breen and Cook 2002; Viana et al. 2013). The primary component of most discard survival studies is fate assignment, whereby 
information about each fish is used to infer its most likely fate (e.g., survival, discard mortality, emigration). Early telemetry studies of fish survival used active tracking to collect data for fate assignment (Bendock and Alexandersdottir 1993), and most assumed any moving tag represented a live fish. However, some authors recognized that transmitters might also move if the study animal had been eaten by a predator (Bacheler et al. 2009), though this was difficult to detect other than by direct observation (e.g., Pepperell and Davis 1999).

The incorporation of sensors into transmitters has allowed for more realistic interpretation of fish tagging data, yet some studies using sensor transmitters still rely primarily on subjective inferences to assign fates (Yergey et al. 2012; Baktoft et al. 2013; Curtis et al. 2015; Runde and Buckel 2018). This methodology can be accurate when fates are obvious; for example, when a transmitter relays constant depth and zero acceleration, the animal is likely either dead or has shed the tag. However, there are scenarios where fates remain ambiguous. For instance, a tagged animal may reside on the boundary of the detectable area, and therefore may provide only a few intermittent pieces of information making inference difficult. Further, for animals and systems where post-release predation or scavenging may be common, distinguishing between the behaviors (e.g., depth, velocity, acceleration) of a live study animal versus a predator that has ingested the tag may be difficult (Jepsen et al. 1998; Gibson et al. 2015). Resolving uncertainty in fate assignment in survival studies is critical for generating accurate and useful results.

More advanced techniques for assigning fates include using a subset of "known-fate" individuals to clarify classification of the remaining subjects. One way to achieve this is to sacrifice some fish prior to tagging and release (i.e., negative control; Muhametsafina et al. 2014). The behavior of these transmitters attached to known dead fish can then be scrutinized and any similar patterns among released-alive fish imply discard mortalities (Yergey et al. 2012; Capizzano et al. 2016). A more opportunistic approach to identify a fate involves re-sighting or recapturing a live tagged animal after a period at large, thereby confirming that all data between release and recapture were generated by that individual and allowing for comparisons as above (i.e., a positive control; Capizzano et al. 2019). Even with these approaches, comparing detection information of known-fate and unknown-fate individuals is typically at best a semi-quantitative procedure (Benoît et al. 2012).

This article is protected by copyright. All rights reserved 
One method for introducing objectivity into fate assignment is with hidden Markov models (HMMs). HMMs are statistical models comprising two processes: an unobserved state process, which represents the underlying dynamics of the observed system, and an observation process. In telemetry studies, the state process has been used as a proxy for the behavior of an animal (e.g., foraging, resting), and it can be inferred from observed movement patterns (Langrock et al., 2012). To date, the utility of HMMs in ecology has been primarily to expand biological knowledge via descriptive studies, though authors have also used HMMs for other purposes (e.g., McClintock et al. 2020). In marine fisheries, HMMs have been applied in studies of spawning behaviors (Holan et al. 2009), behavior in sharks (Papastamatiou et al. 2018), migratory phases of Southern Bluefin Tuna Thunnus maccoyii (Patterson et al. 2009) and Cownose Ray Rhinoptera bonasus (Ogburn et al. 2018), movement types in Gray Triggerfish Balistes capriscus (Bacheler et al. 2019), and behavioral states in Yellowfin Tuna T. albacares and Bigeye Tuna T. obesus (Vermard et al. 2010). However, instead of identifying and classifying behaviors of the tagged animals, it is possible that HMMs could identify changes in movement patterns of the tags which may in fact relate to different animals (e.g., a predator that has eaten a tag). To our knowledge, HMMs have never been used in survival studies where changes in movement patterns may imply predation or scavenging.

Estimates of discard survival are particularly important for fisheries in which discards comprise a large portion of catch (Runde et al. 2019) and discard survival is likely to be low due to gear interactions or barotrauma (Davis 2002). One group of marine fishes for which discard survival is typically low is deepwater groupers. Many species of deepwater groupers in the southeast United States (SEUS) are imperiled in part because they are naturally rare, aggressive, heavily targeted, and susceptible to extreme barotrauma (Huntsman et al. 1999). In fact, barotrauma of fishes in this group is so severe that discard survival is often assumed to be $0 \%$; this assumption is reflected in regulations for species such as Snowy Grouper Hyporthodus niveatus, for which the recreational bag limit in the SEUS is currently one per vessel with no minimum size (SAFMC 2016; Runde and Buckel 2018). Further, several species of groupers in the SEUS are listed as overfished (Snowy Grouper; Red Grouper Epinephelus morio), undergoing overfishing (Speckled Hind E. drummondhayi) or are experiencing a multi-decade decline (Scamp Mycteroperca phenax) (Bacheler and Ballenger 2018; NOAA Fisheries 2018). 
The use of descender devices to recompress barotraumatized fishes has been explored for several species and taxa, including Walleye Sander vitreus (Eberts et al. 2018), Red Snapper Lutjanus campechanus (Drumhiller et al. 2014; Bohaboy et al. 2019), Pacific rockfishes Sebastes spp. (Theberge and Parker 2005), Black Sea Bass Centropristis striata (Rudershausen et al. 2020), and deepwater groupers (Runde and Buckel 2018). Studies testing this technique have generally found increases in survival of fish released with a descender device as compared to without (reviewed by Eberts and Somers 2017). More challenging has been generating precise estimates of survival that are usable for stock assessments and management strategy evaluations and that could be confidently cited as evidence by managers wishing to encourage or require the use of descender devices in the fishery.

Here we use HMMs to quantitatively analyze acoustic telemetry data from several species of deepwater groupers released with descender devices. We build on the findings of Runde and Buckel (2018) by following much of their field methodology but introduce substantial improvements in the approach to analysis and inference. Specifically, we used HMMs to aid in identification of predation or scavenging of the released study animals by examining changes in acceleration and depth. Our results are the first discard survival estimates to be generated with HMMs.

Methods

Study area, fish capture, and tagging

We fished for groupers inside the Snowy Wreck Marine Protected Area (333ํN, $76^{\circ} 50^{\prime} \mathrm{W}$ ) off North Carolina, USA, in May-August, 2018 (Figure 1). Fishing was conducted at the continental shelf break in 66-120 m and at a shipwreck (called the Snowy Wreck) in $240 \mathrm{~m}$. Our methods largely followed those of Runde and Buckel (2018). Briefly, we fished using highlow bottom rigs with size-8/0 hooks baited with cut Atlantic Menhaden Breevortia tyrannus and shortfin squid Illex sp. Upon capture, grouper total lengths (TL) were measured to the nearest 5 $\mathrm{mm}$ and groupers $>350 \mathrm{~mm}$ TL were affixed with Vemco ultrasonic coded transmitters (V13AP$\mathrm{H}$; $69 \mathrm{kHz}$; random delay $=60-180 \mathrm{~s}$; estimated tag life $=158 \mathrm{~d}$ ) via two nylon dart tags to the dorsal musculature (see Figure 1 in Runde and Buckel 2018). V13AP transmitters contain two sensors: depth (via a converted pressure value) and acceleration, produced as an average value over a $45 \mathrm{sec}$ interval. More description of accelerometer / pressure sensors may be found in 
Curtis et al. (2015). Our external attachment procedure shortened the surface interval, isolated the effects of recompression (instead of venting via an incision), and increased detectability of the transmitters (Johnson et al. 2015; Dance et al. 2016). Transmitters were sterilized in diluted $2 \%$ chlorhexidine gluconate prior to attachment, and deck time for each fish was no more than 2 $\min$.

At the continental shelf break, grouper were released by one of three methods. Most groupers were descended with a SeaQualizer ${ }^{\mathrm{TM}}$ descender device set to 30, 61, or $91 \mathrm{~m}$ (the three settings of the SeaQualizer ${ }^{\mathrm{TM}}$ model we used), depending on the bottom depth. The release depth was chosen as the setting that would release the fish as close to the bottom as possible. Four groupers in this treatment group were double-tagged (affixed with two V13AP transmitters, one on each side of the dorsum and offset in the anterior-posterior plane) in an effort to estimate tag retention, as is common in conventional tagging studies (Beverton and Holt 1957; Seber 1982). For the second treatment, some groupers were released boat-side into a bottomless surface enclosure (2.5 m square and $1.3 \mathrm{~m}$ deep) where their behavior was observed and recorded (sensu Hannah et al. 2008). If these groupers floated and appeared moribund, they were assumed to be dead and were recovered, and the transmitter was reused. Finally, a subset of groupers caught at the continental shelf break were sacrificed, tagged as above, and descended to 30, 61, or $91 \mathrm{~m}$ with a SeaQualizer ${ }^{\mathrm{TM}}$ device. These individuals served as a negative control, because any acceleration and depth changes of their transmitters were known to be from scavengers. At the Snowy Wreck, all grouper were descended to the seafloor with a Blacktip ${ }^{\mathrm{TM}}$ descender device in order to promote residency of the transmitter to the site (and detectability on local receivers) as opposed to a mid-water-column release via the SeaQualizer.

\section{Submersible receiver mooring deployment and retrieval}

We deployed an array of 22 Vemco VR2AR acoustic release receivers in the Snowy Wreck Marine Protected Area on May 1, 2018 (Figure 1). Each mooring was anchored with 43 $\mathrm{kg}$ steel sacrificial ballast attached to a receiver lug with $6.4 \mathrm{~mm}$ diameter steel cable. Above each receiver was a subsurface trawl float ( $280 \mathrm{~mm}$ diameter, $8.8 \mathrm{~kg}$ buoyancy) attached with ultra-high molecular weight polyethylene fiber (Dyneema $\left.{ }^{\circledR}\right)$ rope and stainless steel shackles. Twenty receivers were deployed at the continental shelf break in likely areas of grouper catch, based on catches by Runde and Buckel (2018) and Rudershausen et al. (2010) in the same

This article is protected by copyright. All rights reserved 
region. Two VR2AR receivers were deployed at the Snowy Wreck, approximately 100 m apart. We recovered all receivers on October 2, 2018.

\section{Data processing and analysis}

Detection data were downloaded to Vemco VUE software and subjected to the False Detection Analyzer to remove likely erroneous detections. We compiled a detection history of depth and acceleration for each transmitter in R (R Core Team 2019) for use in HMM and assignments of fate. Examples of full time series information for individual fish are located in Figure 3 and Appendix 1.

A hidden Markov model assumes that each observed variable (in our case, acceleration or depth) can arise from several different probability distributions, called emission distributions (Zucchini et al. 2016). An unobserved state process $S_{t}$ determines which distribution is active at each time $t$, and its evolution is modelled with transition probabilities. In preliminary analyses, we fitted models with 2, 3, and 4 states, and found that the 3 -state model was a good compromise to obtain biologically interpretable states. Two of these states appeared to capture the behavioral heterogeneity in the movement of live groupers (we do not attempt to assign a more specific description in this paper), and the third state served as a proxy for the movement of groupers' predators. Our 3-state HMM resulted in nine transition probabilities

$$
\left(\begin{array}{lll}
\gamma_{11} & \gamma_{12} & \gamma_{13} \\
\gamma_{21} & \gamma_{22} & \gamma_{23} \\
\gamma_{31} & \gamma_{32} & \gamma_{33}
\end{array}\right)
$$

Where $\gamma_{\mathrm{ij}}=\operatorname{Pr}\left(S_{t+1}=j \mid S_{t}=i\right)$ is the probability of a transition from state $i$ to state $j$ over one time interval. HMMs require data streams to be on a regularized time grid (e.g., one observation every $30 \mathrm{~min}$ ). Given that our V13AP tags transmitted on a random delay, our detection data were not regularized temporally. Therefore, we binned detections into $30 \mathrm{~min}$ time bins for the purpose of regularization. We chose an interval long enough so that most time bins contained one observation or more, and short enough to capture the movement states of interest (see Discussion). Based on qualitative examination of the binned detection data, we generated three informative data streams that were used as inputs in our HMM. The first data stream was mean acceleration $\left(\mathrm{m} / \mathrm{s}^{2}\right)$ for the 30 -minute bin, denoted by $Z_{1 t}$, and was parameterized as a gamma 
distribution. Acceleration is a proxy for the level of activity of the animal, and we expect the levels of activity of groupers and their predators to be different. Therefore, we would expect the distributions of accelerations from a live grouper and a dead grouper to be different. The second data stream was mean depth as a proportion of release depth (m), denoted by $Z_{2 t}$, where a value of 1.0 represented the fish being detected at exactly the same depth as was recorded during capture. This transformation was necessary as the study animals were released across a range of depths and therefore serves as a proxy for distance from the seafloor. For example, two surviving grouper released in areas where the seafloor was 60 and $120 \mathrm{~m}$ respectively would have drastically different absolute depth values and erroneously have different states in HMM model when their survival is the same; normalizing by release depth allows for a comparison of relative depth movements. Given the different biology of demersal fishes and their likely predators (for large groupers, elasmobranchs), we expected different depth utilizations. This data stream was also parameterized as a gamma distribution. Finally, the third data stream was the standard deviation of all depth values in each time bin, denoted by $Z_{3 t}$. Standard deviation in depth is a proxy for the rate of movement of the fish in the vertical dimension. We did not expect normal grouper behavior to involve rapid up/down movements, though this type of behavior is likely in elasmobranchs. This final data stream was again parameterized as a gamma distribution. Using both a value for relative depth and a value for standard deviation of depth for each time bin offer a more adequate characterization of the vertical movements of each fish in each bin than would one of these variables alone. Both are needed to determine whether a fish was shallow or deep (relatively) as well as changing depth regularly or at a stationary depth. The observation model can therefore be written

$$
\begin{aligned}
& Z_{1 t} \sim \operatorname{gamma}\left(\theta_{1 j}, \theta_{2 j}\right) \\
& Z_{2 t} \sim \operatorname{gamma}\left(\theta_{3 j}, \theta_{4 j}\right) \\
& Z_{3 t} \sim \operatorname{gamma}\left(\theta_{5 j}, \theta_{6 j}\right)
\end{aligned}
$$

in state $S_{t}=j=\in\{1,2,3\}$ where the $\theta_{i j}$ are state-dependent observation parameters. HMMs and subsequent analyses were performed in the R package 'momentuHMM' (McClintock and Michelot 2018).

Fate assignment and survival estimation

This article is protected by copyright. All rights reserved 
Results from the HMM were examined and data for each individual grouper were used to assign fates. We compared the state sequences of the sacrificed descended individuals (i.e., negative control) to the state sequences of the descended-alive individuals. If descended-alive groupers displayed the same state as the negative controls, they were determined to be deceased and subject to predation or scavenging. The state sequences for groupers displaying other states were scrutinized and used to make informed decisions about their assigned fates. Emigration of a live grouper was determined to have occurred if detections ceased without switching to a state representing predation. Tag loss was determined to have occurred if depth became near constant and acceleration became zero simultaneously and remained in those conditions until the terminal detection. Groupers that emigrated from the receiver array or lost their tag were censored from the analysis on the day of emigration or tag loss.

We assigned fates using two general scenarios. In Analysis 1, we assigned fates based more strictly on HMM results; we imposed expert knowledge only when the fates suggested by HMMs were illogical (e.g., a grouper displaying brief periods of a predator-like state surrounded by months of grouper-like states was not considered to have been temporarily dead). In Analysis 2, we allowed for behaviors and phenomena that have been anecdotally observed in other studies but could not be confirmed here (e.g., vertical movement of live study animals before emigration from the receiver array; N. Wegner, unpublished data). Furthermore, in Analysis 2 we took into account ancillary data that could not be included in the HMM, such as any information about a transmitter's movement through space on different receivers. For example, if a transmitter was detected twice in a very short period of time on receivers that were several kilometers apart, we considered this to be evidence of possible predation. The fate assignments from Analysis 1 are generally more conservative (i.e., they err on the side of lower survival).

Fates for groupers that were released alive were used to inform Kaplan-Meier nonparametric models to estimate post-release survival. We conducted separate Kaplan-Meier procedures for groupers released via descending, released into the surface enclosure, and for releases at the Snowy Wreck; estimates were generated twice for each of these groups (once each for Analysis 1 and Analysis 2). The Kaplan-Meier procedures were conducted in the R package 'survminer' (Kassambara and Kosinski 2018).

Results

This article is protected by copyright. All rights reserved 
At the continental shelf break (depth $=66-120 \mathrm{~m}$ ), we released 40 groupers via descending, of which four were double tagged. In addition, we released nine groupers into the bottomless surface enclosure. Of these nine surface releases, two groupers swam down and seven floated. The seven groupers that floated were recovered and their tags reused; those reused tags are included in totals below. We sacrificed and descended three tagged groupers for a total of 45 individuals released at the shelf break (40 descended alive, two surface released that swam down, and three dead). At the Snowy Wreck (depth $=240 \mathrm{~m}$ ), we tagged and released five Snowy Groupers, all of which were descended to the seafloor. Overall, we tagged at least one individual of six grouper species: Gag M. microlepis $(\mathrm{n}=1)$, Red Grouper $(\mathrm{n}=1)$, Scamp $(\mathrm{n}=11)$, Snowy Grouper ( $\mathrm{n}=31+5$ at the Snowy Wreck), Speckled Hind $(\mathrm{n}=4)$, and Yellowmouth Grouper $M$. interstitialis $(\mathrm{n}=4)$. Total lengths, depths of capture, species identification, and treatments for each individual are shown in Table 1.

We obtained over 580,000 detections from telemetered groupers. These detections were from each of the 50 groupers in the study that submerged. Across all individuals, we created 60,666 30-min time bins. Parameter estimates for the emission distributions for each data stream were estimated (Table 2). Estimates of the parameters of the emission distributions showed clear distinctions between the three states (Table 2; Figure 2). State 1 was characterized by the lowest mean acceleration ("Acc") values, the closest relative depth ("RelDepth") to 1.0, and the lowest mean standard deviation of depth ("DepthSD"). State 2 had similar Acc values to state 1, but had a mean RelDepth of 1.10 (the highest of the three states), and a moderate DepthSD mean. State 3 showed the highest mean Acc, the only RelDepth mean less than 1.0 (indicating depths well above tagging depth), and the largest DepthSD value. State transition probabilities were

$$
\left(\begin{array}{lll}
0.994 & 0.004 & 0.001 \\
0.009 & 0.990 & 0.001 \\
0.007 & 0.004 & 0.989
\end{array}\right)
$$

Of the three sacrificed and descended dead groupers, only one provided sufficient data to be included in the HMM (Scamp 3). The other two individuals (Snowy Grouper 11 and Snowy Grouper 5) were detected for approximately 7 and 25 minutes respectively, and each had very few detections. The terminal detection for each of these individuals suggested the transmitter was within a few meters of the surface. Scamp 3 was detected for approximately 26 hours. The HMM classified this individual as exhibiting state 3 throughout the entire time period for which it was 
detected (Figure 3A). We reviewed the state sequences for the remaining individuals, and those dominated by states 1 and 2 were categorized as survivals (e.g., Figure 3B).

For 40 groupers descended alive at the shelf break, Analysis 1 determined 14 had survived the duration of the study, three lost their tags while still alive, one emigrated, and 22 experienced discard mortality. For the same fish, fates determined using Analysis 2 differed for 11 individuals; in general, this procedure changed fates from mortalities to emigration or tag loss based on previous authors' observations of post-tagging recovery behavior in demersal fishes (e.g., Collins 2014; see Discussion). Further, the HMM was not able to distinguish between a dead grouper on the seafloor (with occasional movement caused by scavengers) and a live grouper. These two interpretations of the same general "behavior" is reflected in the differences between the two Analyses. Analysis 2 determined 14 grouper survived the duration of the study, four lost their tags while still alive, seven emigrated, and 15 experienced discard mortality. In Analysis 1, each of the four double-tagged groupers experienced mortality within the first day after release. In Analysis 2, one died, two emigrated in the first two days, and one appeared to lose one tag within hours of release and then emigrate on day 4. We conclude that tag loss is possible given this attachment type, though the sample sizes and durations of observation for double-tagged fish preclude a statistical estimate of that rate. Fates for each individual assigned in both Analyses are shown in Table 1.

All mortalities occurred within the first seven days after tagging, therefore our survival estimate at that time represents our estimate for the study overall. For groupers descended alive at the shelf break, the Kaplan-Meier survivorship procedure using Analysis 1 fates generated a survival estimate of 0.46 (95\% confidence interval 0.33, 0.65; Figure 4). Using Analysis 2 fates, the survival estimate was $0.61(0.47,0.80)$.

Two of nine surface-released groupers swam down; under Analysis 1, both of these fish appeared to experience mortality on the day they were tagged (day zero), resulting in survival of 0.00. Under Analysis 2, these two fish could have emigrated on days 1 and 5 respectively. Using these fates, a Kaplan-Meier survivorship procedure estimates survival of $0.22(0.07,0.75)$ for surface-released groupers. Of five groupers released at the Snowy Wreck in $240 \mathrm{~m}$, none survived beyond day zero using Analysis 1 fates, resulting in a survival estimate of 0.00 . Analysis 2 interpretations suggest that all five may have emigrated within 9 days based on their 
disappearance from the receiver array (but see Discussion). Thus, no conclusions can be robustly drawn for groupers released at the Snowy Wreck given the survival estimates (0.00 to 1.00) from Analysis 1 and 2.

\section{Discussion}

The objectivity for fate assignment provided by hidden Markov models is a major improvement to telemetry-based survival studies. We found that in most cases the HMM could distinguish between known-dead individuals and groupers we believe to have been alive during the study period. However, generating a survival estimate from HMMs still required subjective assignment of fates for some individuals; we describe these procedures and other caveats below.

In our study, there were a few groupers for which the HMM identified mortalities that subjective inference would likely have missed. These animals represent one of the major utilities of HMMs. For Scamp 6 (Appendix 1; figures are ordered by species and individual), Snowy Grouper 3 (Figure 3C), and Speckled Hind 4 (Appendix 1), initial examination of the acoustic profiles suggested tag loss, and we would likely have considered these fish alive using subjective inference alone. However, the HMM identified clear changes in the states of these three individuals (from states 1 and 2 to state 3 ) several days prior to flat-lined depth and acceleration. We therefore concluded that these individuals were alive and then eaten by a predator. These three groupers exhibited state 3 for four days, five days, and one day prior to apparent expulsion of the transmitter by the predator. These durations fall within the usual gastric evacuation time of most large elasmobranchs (Wetherbee and Cortés 2004). Furthermore, during the period after apparent predation for each of these three fish detections were recorded on several (four or more) receivers, suggesting the transmitter was in an extremely mobile animal.

Contrary to the above individuals, where we assigned mortalities based on HMM results, there were several fish for which we used ancillary information to overrule HMM results. For example, Scamp 10 was assigned state 3 for the entirety of its detection history (Figure 3D). Scamp 10 was relatively small (490 mm TL), but was tagged with a transmitter that had been prepared for a larger fish. The wires connecting the tag to the dart tips were therefore longer than necessary. The first author noted that the tag appeared loose upon release. This situation appears to be reflected in the acceleration profile for this fish: there are no observations of zero acceleration until the tag was evidently lost on day six. Because the depth detections for Scamp 
10 resemble depths for live groupers, we categorized this individual as alive until tag loss in both Analysis 1 and Analysis 2. All other groupers were tagged with transmitters with wire lengths appropriate for their body size.

In addition to Scamp 10, there were several individuals that transitioned to state 3 or disappeared after several days of states 1 and 2. Examination of these profiles revealed that some showed almost no changes in depth and few non-zero acceleration detections until their transition to state 3 or disappearance (e.g., Snowy Grouper 20; Figure 3E). This type of detection profile may represent a dead grouper on the seafloor being scavenged by smaller fish and invertebrates with intermittent occurrences of being picked up by a (perhaps larger) scavenger (signaled by a switch to state 3) on (in the case of Snowy Grouper 20) August 30 and again on September 8 . These brief, rapid, vertical movements from a near-constant depth of $120 \mathrm{~m}$ to depths as shallow as $60 \mathrm{~m}$ are a behavior we never observed in groupers we categorized as alive. Live groupers sometimes exhibited zero acceleration and no changes in depth, but these periods were punctuated with regular movements detected by both sensors. This regular movement was not observed in the several fish we believe may have been dead and experiencing seafloor scavenging. There were nine individuals for which this potential on-seafloor scavenging was observed. The majority of these were categorized by the HMM as states 1 and 2 for much of their observation period but state 3 at the end of their detection history. Contrary to scavenging events during which the predator ingested the transmitter and rose into the water column, onseafloor scavenging appears to the HMM to be similar to live grouper behavior (i.e., states 1 and 2). For Analysis 1, these individuals were considered mortalities on day 0. Under Analysis 2, we considered the possibility that these fish were alive and recovering from the stress associated with capture, tagging, and release, and emigrated after or during this recovery period by first migrating vertically. Collins (2014) and Runde and Buckel (2018) described a post-tagging recovery period during which fish were less active. As none of the descended dead groupers exhibited this type of profile, these individuals were therefore considered alive until the point of emigration in Analysis 2. Recovery followed by emigration behavior has been observed in Pacific rockfishes, some of which were later recaptured, thereby confirming their status as live fish (N. Wegner, NMFS, pers. comm.). Unfortunately, we were unable to recapture any telemetered fish in this study; therefore, the interpretation of these animals' behavior remains 
uncertain. We recommend future telemetry studies tag a larger sample size of sacrificed individuals.

We identified some groupers that clearly lost their transmitter (either while still alive or postmortem) prior to the end of the study, as they displayed zero acceleration and constant depth after a certain point. The data file for each of these fish was truncated to remove the detections representing a lost tag, as these tag loss data would not correspond to any of the movement states of the HMM. We considered the possibility of a 4-state HMM, where the additional state would represent these data. However, this was not feasible given our use of relative depth as a datastream for the HMM. Indeed, the distribution of relative depths was not consistent across lost tags, because transmitters were lost at relative depths ranging from approximately 0.56 to 1.95. This wide range is a result of the high relief habitat in which we performed our study; future studies conducted in lower relief areas may have success modeling tag loss as its own HMM state.

Choosing the number of states in HMMs is challenging, and often not straightforward (Pohle et al., 2017). In this study, we investigated HMMs with two and four states in addition to the eventual 3-state model. The 2-state model did not appropriately distinguish the descendeddead grouper from the released-alive fish. In the 4-state model, the additional state emerged as something of a midpoint between states 2 and 3, which obfuscated the results rather than clarifying them. We determined that the 3-state model was necessary to capture the complexity of the situation to which we were attempting to apply HMMs but not so state-heavy that the results were difficult or impossible to glean. We lacked the data that are perhaps most typical as inputs for HMMs applied to animal movement: turning angle and step length. Instead, we used alternative data streams to characterize movement, e.g., depth relative to depth at release was chosen as a proxy for distance from the seafloor. We note that some groupers may have consistently occupied seafloor habitat but appear to sometimes be much deeper or much shallower than their release depth (e.g., Red Grouper 1; Figure 3F). This possibly occurred because the shelf break consists of many areas of extreme depth changes over a short linear distance; Red Grouper 1 appeared to prefer seafloor habitat in two primary depths that were $\sim 20$ $\mathrm{m}$ different yet still within the receiver array. Because of the variation in this and other individuals, the live grouper detection information for all three data streams contained a wide 
range of values, which resulted from not only a variety of "normal" grouper behaviors but also from the imperfection of the data streams available in this study.

Typical HMMs for animal movement result in biological description of the behavioral states identified such as "foraging” or "transiting" (e.g., Bacheler et al. 2019). For our purposes, such description is a dubious exercise given the data streams we had available. States 1 and 2 seemed to define animals that accelerate at a relatively low amount, occupy habitat close to the seafloor, and change depths a low to moderate amount. State 3 was described by animals that have higher acceleration, utilize a much wider range of depths, and change depth rapidly. These qualitative descriptions of the states are consistent with our assertion that states 1 and 2 represent live groupers and state 3 serves as a reasonable proxy for groupers eaten by predators, though without recapture of tagged groupers or of predators containing grouper tags, confirmation of these assertions is impossible. In cases where the fate of some of the fish is known, this information can also be included in the HMM to clarify the classification of the other tracks ("semi-supervised learning," Leos- Barajas et al. 2017). Future work including a greater number and variety of known-fate individuals could attempt this approach.

The mathematical formulation of discrete-time models (like the HMMs used here) is tied to a particular time interval of observation, necessitating the regularization of the data. We considered applying a continuous-time model to these data given the irregularity of the detections. Indeed, continuous-time models make no assumption about the time resolution of the data, and offer a more natural description of the continuous movement of animals. However, the implementation of state-switching continuous-time models is much more difficult and computational than using HMMs (Blackwell et al. 2016; Michelot and Blackwell 2019). In particular, continuous-time methodology has focused on the analysis of longitude-latitude movement data, and it may not be straightforward to adapt it to the acceleration and depth variables used in this study. Further, there are no accessible software packages to apply those models to telemetry data sets, and the large size of our data set ( 60,000 time bins) would make the model fitting time-consuming. For these reasons, we opted for a more standard discrete-time approach, and recommend that continuous-time methods could be explored in future research.

The duration of time bins for discrete-time models can influence results. In addition to 30-minute bins, we investigated the use of 15- and 60-minute intervals. Neither of these models 
resulted in different fate assignments than the 30-minute version. We elected to use 30 minutes because the proportion of bins with no data was much lower than the 15-minute version. In addition, we wished to use a fine enough temporal resolution that our model would not obscure the biological reality of behavioral changes. Thirty-minute bins seemed a good compromise for this purpose.

Our survival estimate from Analysis 1 of $0.46(0.33,0.65)$ and from Analysis 2 of 0.61 $(0.47,0.80)$ fall within the range estimated by Runde and Buckel (2018). Their survival estimate of $0.50(0.10,0.91)$ had extremely broad confidence intervals because many emigrations exacerbated an already-low sample size. Our higher sample size and larger array, paired with more precise fate assignments via HMM, produced much narrower confidence intervals in the present study. However, uncertainty in state determination from the HMM was not propagated into our final fate assignment and therefore variance may be underestimated. When discard survival is used as a stock assessment input, we recommend examining its effect via sensitivity analysis or other means to quantify uncertainty in model output. Other studies examining the effects of descender devices in this depth range are scarce, though some have been conducted in slightly shallower marine environments. Curtis et al. (2015) worked in 50m and estimated survival of descended Red Snapper as 0.83 (0.68, 0.98). Sumpton et al. (2010) tagged red emporer L. sebae in depths predominantly $>30 \mathrm{~m}$ but found little evidence for descender devices promoting survival in this species. We recommend future descender device studies work in depths and habitats that are most relevant to the fishery.

We elected to analyze survival across species for several reasons. First, given the high cost of acoustic telemetry, our sample sizes by species were limited. Second, many of these species cohabitate, and most groupers in the SEUS are managed as an aggregate unit (SAFMC 2016), so our findings are applicable to the fishery in general. When analyzed separately, the two species for which we had the highest sample sizes at the shelf break, Snowy Grouper and Scamp, had survival estimates of $0.49(0.32,0.76)$ and $0.38(0.15,0.92)$ respectively in Analysis 1 , and the two species had estimates of $0.79(0.62,1.00)$ and $0.31(0.10,0.96)$ respectively in Analysis 2. The majority of these mean estimates are near our overall estimates of 0.46 and 0.62 , and all of the confidence intervals overlap widely, supporting our choice to pool the species-specific estimates.

This article is protected by copyright. All rights reserved 
Current management assumes discard survival of zero for many reef fishes due to extreme barotrauma (SAFMC 2016). In the present study, we made an attempt to gather evidence on this topic by releasing tagged groupers into our bottomless surface enclosure. Since our maximal mean estimate of survival (Analysis 2) for nine groupers released at the surface in this study is 0.22 , we are inclined to agree in principle with the current assumption of zero survival for the species examined, though a low level of survival may be possible particularly in the shallower portion of these species' ranges. However, we have demonstrated that survival is significantly higher than zero for groupers released with a descender device. The South Atlantic Fishery Management Council recently approved Regulatory Amendment 29 to the SnapperGrouper Fishery Management Plan, which requires the presence of descender devices on board vessels fishing for reef fish in the southeast US (implemented June 2020). Given our findings, we recommend other management agencies take similar measures to promote widespread use of descender devices in this and other fisheries.

Many of our groupers, including all five released at the Snowy Wreck, may have succumbed to predation after release. While Analysis 2 allows for the possibility of emigration for these individuals, we believe that explanation to be unlikely. Three out of five of these fish were detected mid-water-column during their detection history at depths of $22 \mathrm{~m}, 26 \mathrm{~m}$, and 71 $\mathrm{m}$. Ambient pressure at $100 \mathrm{~m}$ is $25 \mathrm{~atm}$; the shallower depths where we detected these individuals has ambient pressure of as low as $3 \mathrm{~atm}$. The barotrauma that is likely to be sustained by a Snowy Grouper transitioning between these two depths is probably prohibitive of such movement being voluntary. Therefore, the depth of the Snowy Wreck may be beyond the maximum depth for which groupers can survive the barotraumatic effects of capture, even if released with a descender device. However, the possibly absolute mortality we observed at that site may have partially resulted from a high density of predators in the area.

Throughout our study, we detected several acoustically tagged elasmobranchs inside our receiver array; at the shelf break, we detected one Tiger Shark Galeocerdo cuvier and five White Sharks Carcharodon carcharias over the five month period for which our receivers were deployed. At the Snowy Wreck, receivers were in place for eighteen months, over which we detected one tiger shark and eight white sharks. Total lengths of these predators ranged from 3.1 $\mathrm{m}$ to $4.2 \mathrm{~m}$ for Tiger Sharks (B. Frazier, pers comm) and $3.3 \mathrm{~m}$ to $4.3 \mathrm{~m}$ for White Sharks ( $G$. 
Skomal and M. Winton, pers comm). Sharks were detected in every month of the study in both locations, supporting the idea that these species (or others) may have been responsible for the predation of our tagged groupers. It is likely that descended groupers displayed abnormal behavior immediately after release, perhaps during recovery from barotrauma (Collins 2014; Runde and Buckel 2018). This behavior is possibly linked to an increased risk of predation, as elasmobranch predators have been shown to preferentially feed on prey that are struggling or displaying irregular behavior (Kritzler and Wood 1961; Dijkgraaf 1963; Bleckmann and Hofmann 1999). It is conceivable that some of the groupers that died after release might have survived if they were able to avoid predation during their recovery period. Some of the groupers may have been deceased prior to ingestion by a predator though some may have been attacked while alive. This is supported by detection data showing depth and acceleration movements typical of a live grouper prior to switching to state 3 (e.g., Scamp 6). Furthermore, we assume that tagging itself did not increase the risk of predation; if any tagged groupers died as a result of tagging, our estimate of survival after recompression would be lower than when realized in the fishery.

External tagging with acoustic transmitters has increased in popularity due to increased detection ranges (Dance et al. 2016) and, for survival studies, the desire to separate the effects of barotrauma with possible relief caused by tagging (Johnson et al. 2015). Attachment methods have ranged from the dart tag style used here and by Runde and Buckel (2018), a method by which the transmitter is glued to a t-bar tag (Yergey et al. 2012), procedures involving "cinchup" tags used by Curtis et al. (2015), methods using suture material passed through the fish by Bacheler et al. (2019), and attachment via an intramuscular stainless steel bolt by Bohaboy et al. (2019). To our knowledge no attempts have been made to quantify tag loss in situ for any of these methods, though some authors used tank holding studies to this end (e.g., Bacheler et al., 2019). Therefore, there is no resolution as to the best tag attachment procedure for such studies. Our attempt to quantify tag loss by double tagging groupers was unsuccessful, as zero of four double-tagged fish survived beyond day zero. This is perhaps because the injury caused by the introduction of four darts was substantially greater than that caused by two darts. Alternatively, the slightly longer surface interval required to tag a fish twice may have resulted in increased mortality risk. It is also possible that these four animals would have experienced mortality if they were tagged only once, and that we simply required a larger sample size to reach a conclusion. 
As is done for conventional tagging, we recommend studies using external attachment of acoustic transmitters make attempts to quantify tag loss in situ, particularly when fate assignment is difficult due to the study animal or habitat. Double tagging with acoustic transmitters, though costly, is likely a sufficient means to that end.

\section{Conclusions}

Survival studies often rely on subjectivity when assigning fates of tagged animals. Recent advancements in transmitter technology have resulted in a greater variety of data available to researchers, but methods for quantitative analysis thereof are lacking. We successfully employed hidden Markov models as a means of increasing objectivity of fate assignment in our study. While our methods and results are imperfect, and still included some subjectivity and additional information (e.g., detection on different receivers in a short time period), future researchers should consider HMMs when attempting to determine fates of animals tagged with acoustic transmitters.

Our result that all surface-released groupers may have died corroborates the assumed $100 \%$ discard mortality for many of species in this group when untreated with a descender device. When taken in context with our survival estimates of 0.46 and 0.61 at the shelf break, this information is extremely valuable for reef fish managers. In addition, our result of perhaps zero survival for groupers released in much deeper water suggests that the recent descender device requirement in the South Atlantic region may not achieve the desired effect, even if compliance is high. Given that descender devices may not be effective in very deep water and that grouper survival in shelf break waters is still relatively low even when descended, it may be necessary for managers to take additional measures (such as spatial closures) to protect imperiled species from overfishing.

\section{Acknowledgments}

Funding for this work was provided by the NOAA Saltonstall-Kennedy Program (\#NA17NMF4270204). For assistance in the field, we thank P. Rudershausen, J. Styron, D. 
Wells, K. Johns, D. Berrane, D. Britt, P. Dufour, E. Scheeler, E. Ebert, R. Gallagher, C. Mikles, J. Fader, O. Mulvey-Mcferron, K. Erickson, A. Matthews, and T. Burgess. We gratefully acknowledge J. Locascio for the extended use of two receivers and N. Wegner for his thoughts on fate assignment. We thank J. Cao for reviewing an early draft of this paper. Scholarship support for B. Runde was provided by the Steven Berkeley Marine Conservation Fellowship, the Joseph E. and Robin C. Hightower Graduate Student Award in Fisheries and Wildlife Sciences, and the North Carolina Wildlife Federation. The scientific results and conclusions, as well as any views and opinions expressed herein, are those of the authors and do not necessarily reflect those of any government agency or institution. There is no conflict of interest declared in this article.

\section{References}

Bacheler, N. M., and J. C. Ballenger. 2018. Decadal-scale decline of Scamp (Mycteroperca phenax) along the southeast United States Atlantic coast. Fisheries Research 204: 74-87.

Bacheler, N. M., J. A. Buckel, J. E. Hightower, L. M. Paramore, and K. H. Pollock. 2009. A combined telemetry-tag return approach to estimate fishing and natural mortality rates of an estuarine fish. Canadian Journal of Fisheries and Aquatic Sciences 66:1230-1244.

Bacheler, N. M., T. Michelot, R. T. Cheshire, and K. W. Shertzer. 2019. Fine-scale movement patterns and behavioral states of Gray Triggerfish Balistes capriscus determined from acoustic telemetry and hidden Markov models. Fisheries Research 215:76-89.

Baktoft, H., K. Aarestrup, S. Berg, M. Boel, L. Jacobsen, A. Koed, M. W. Pedersen, J. C. Svendsen, and C. Skov. 2013. Effects of angling and manual handling on pike behaviour investigated by high- resolution positional telemetry. Fisheries Management and Ecology 20:518-525.

Bendock, T., and M. Alexandersdottir. 1993. Hooking mortality of Chinook Salmon released in the Kenai River, Alaska. North American Journal of Fisheries Management 13:540-549.

Benoît, H. P., T. Hurlbut, J. Chassé, and I. D. Jonsen. 2012. Estimating fishery-scale rates of discard mortality using conditional reasoning. Fisheries Research 125:318-330.

Beverton, R., and S. J. Holt. 1957. On the Dynamics of Exploited Fish Populations, Vol. II of Fishery Investigations, Ministry of Agriculture. Fisheries and Food. 
Blackwell, P. G., M. Niu, M. S. Lambert, and S. D. LaPoint. 2016. Exact Bayesian inference for animal movement in continuous time. Methods in Ecology and Evolution, 7: 184-195.

Bleckmann, H., and M. H. Hofmann. 1999. Special senses. Sharks, Skates and Rays: the Biology of Elasmobranchs:300-328.

Bohaboy, E. C., T. L. Guttridge, N. Hammerschlag, M. P. M. Van Zinnicq Bergmann, and W. F. Patterson, III. 2019. Application of three-dimensional acoustic telemetry to assess the effects of rapid recompression on reef fish discard mortality. ICES Journal of Marine Science.

Breen, M., and R. Cook. 2002. Inclusion of discard and escape mortality estimates in stock assessment models and its likely impact on fisheries management. ICES CM 27:15.

Brill, R., M. Lutcavage, G. Metzger, P. Bushnell, M. Arendt, and J. Lucy. 2002. Survival of juvenile Northern Bluefin Tuna following catch and release, using ultrasonic telemetry. Pages 180-183 in American Fisheries Society Symposium. American Fisheries Society.

Capizzano, C. W., J. W. Mandelman, W. S. Hoffman, M. J. Dean, D. R. Zemeckis, H. P. Benoît, J. Kneebone, E. Jones, M. J. Stettner, and N. J. Buchan. 2016. Estimating and mitigating the discard mortality of Atlantic Cod (Gadus morhua) in the Gulf of Maine recreational rod-and-reel fishery. ICES Journal of Marine Science 73:2342-2355.

Capizzano, C. W., D. R. Zemeckis, W. S. Hoffman, H. P. Benoît, E. Jones, M. J. Dean, N. Ribblett, J. A. Sulikowski, and J. W. Mandelman. 2019. Fishery-scale discard mortality rate estimate for Haddock in the Gulf of Maine recreational fishery. North American Journal of Fisheries Management 0.

Collins, A. 2014. An investigation into the habitat, behavior and opportunistic feeding strategies of the protected Goliath Grouper (Epinephelus itajara). Doctoral dissertation. University of South Florida, Tampa, Florida.

Crossin, G. T., M. R. Heupel, C. M. Holbrook, N. E. Hussey, S. K. Lowerre- Barbieri, V. M. Nguyen, G. D. Raby, and S. J. Cooke. 2017. Acoustic telemetry and fisheries management. Ecological Applications 27:1031-1049.

Curtis, J. M., M. W. Johnson, S. L. Diamond, and G. W. Stunz. 2015. Quantifying delayed mortality from barotrauma impairment in discarded Red Snapper using acoustic telemetry. Marine and Coastal Fisheries 7:434-449.

This article is protected by copyright. All rights reserved 
Dance, M. A., D. L. Moulton, N. B. Furey, and J. R. Rooker. 2016. Does transmitter placement or species affect detection efficiency of tagged animals in biotelemetry research? Fisheries Research 183:80-85.

Davis, M. W. 2002. Key principles for understanding fish bycatch discard mortality. Canadian Journal of Fisheries and Aquatic Sciences 59:1834-1843.

Dijkgraaf, S. 1963. The functioning and significance of the lateral- line organs. Biological reviews 38:51-105.

Drumhiller, K. L., M. W. Johnson, S. L. Diamond, M. M. Reese Robillard, and G. W. Stunz. 2014. Venting or rapid recompression increase survival and improve recovery of Red Snapper with barotrauma. Marine and Coastal Fisheries 6:190-199.

Eberts, R. L., and C. M. Somers. 2017. Venting and descending provide equivocal benefits for catch- and- release survival: study design influences effectiveness more than barotrauma Relief Method. North American Journal of Fisheries Management 37:612-623.

Eberts, R. L., M. A. Zak, R. G. Manzon, and C. M. Somers. 2018. Walleye responses to barotrauma relief treatments for catch-and-release angling: short-term changes to condition and behavior. Journal of Fish and Wildlife Management 9:415-430.

Gibson, A. J. F., E. A. Halfyard, R. G. Bradford, M. J. Stokesbury, and A. M. Redden. 2015. Effects of predation on telemetry-based survival estimates: insights from a study on endangered Atlantic Salmon smolts. Canadian Journal of Fisheries and Aquatic Sciences 72:728-741.

Gorsky, D., J. Zydlewski, and D. Basley. 2012. Characterizing seasonal habitat use and diel vertical activity of Lake Whitefish in Clear Lake, Maine, as determined with acoustic telemetry. Transactions of the American Fisheries Society 141:761-771.

Halfyard, E. A., D. Webber, J. Del Papa, T. Leadley, S. Kessel, S. Colborne, and A. Fisk. 2017. Evaluation of an acoustic telemetry transmitter designed to identify predation events. Methods in Ecology and Evolution 8:1063-1071.

Hannah, R. W., S. J. Parker, and K. M. Matteson. 2008. Escaping the surface: the effect of capture depth on submergence success of surface-released Pacific rockfish. North American Journal of Fisheries Management 28:694-700.

Holan, S. H., G. M. Davis, M. L. Wildhaber, A. J. DeLonay, and D. M. Papoulias. 2009. Hierarchical Bayesian Markov switching models with application to predicting spawning

This article is protected by copyright. All rights reserved 
success of Shovelnose Sturgeon. Journal of the Royal Statistical Society: Series C (Applied Statistics) 58:47-64.

Huntsman, G., J. Potts, R. Mays, and D. Vaughan. 1999. Groupers (Serranidae, Epinephelinae): endangered apex predators of reef communities. Pages 217-231 in American Fisheries Society Symposium.

Jepsen, N., K. Aarestrup, F. Økland, and G. Rasmussen. 1998. Survival of radiotagged Atlantic Salmon (Salmo salar)-and trout (Salmo trutta) smolts passing a reservoir during seaward migration. Hydrobiologia 371:347.

Johnson, M. W., S. L. Diamond, and G. W. Stunz. 2015. External attachment of acoustic tags to deepwater reef fishes: an alternate approach when internal implantation affects experimental design. Transactions of the American Fisheries Society 144:851-859.

Kassambara, A., and M. Kosinski. 2018. survminer: Drawing Survival Curves using 'ggplot2'. R package version 0.4.3. https://CRAN.R-project.org/package=survminer

Kays, R., M. C. Crofoot, W. Jetz, and M. Wikelski. 2015. Terrestrial animal tracking as an eye on life and planet. Science 348:aaa2478.

Kritzler, H., and L. Wood. 1961. Provisional audiogram for the shark, Carcharhinus leucas. Science 133:1480-1482.

Langrock, R., R. King, J. Matthiopoulos, L. Thomas, D. Fortin, and J. M. Morales. 2012. Flexible and practical modeling of animal telemetry data: hidden Markov models and extensions. Ecology 93:2336-2342.

Leos- Barajas, V., T. Photopoulou, R. Langrock, T. A. Patterson, Y. Y. Watanabe, M. Murgatroyd, and Y. P. Papastamatiou. 2017. Analysis of animal accelerometer data using hidden Markov models. Methods in Ecology and Evolution 8:161-173.

McClintock, B. T., and T. Michelot. 2018. momentuHMM: R package for generalized hidden Markov models of animal movement. Methods in Ecology and Evolution 9:1518-1530.

Michelot, T., and P. G. Blackwell. 2019. State- switching continuous- time correlated random walks. Methods in Ecology and Evolution, 10: 637-649.

Muhametsafina, A., J. Midwood, S. Bliss, K. Stamplecoskie, and S. Cooke. 2014. The fate of dead fish tagged with biotelemetry transmitters in an urban stream. Aquatic ecology 48:23-33.

NOAA Fisheries. 2018. 2018 Report to Congress on the Status of U.S. Fisheries

This article is protected by copyright. All rights reserved 
Ogburn, M. B., C. W. Bangley, R. Aguilar, R. A. Fisher, M. C. Curran, S. F. Webb, and A. H. Hines. 2018. Migratory connectivity and philopatry of Cownose Rays Rhinoptera bonasus along the Atlantic coast, USA. Marine Ecology Progress Series 602:197-211.

Papastamatiou, Y. P., Y. Y. Watanabe, U. Demšar, V. Leos-Barajas, D. Bradley, R. Langrock, K. Weng, C. G. Lowe, A. M. Friedlander, and J. E. Caselle. 2018. Activity seascapes highlight central place foraging strategies in marine predators that never stop swimming. Movement ecology 6:9.

Patterson, T. A., M. Basson, M. V. Bravington, and J. S. Gunn. 2009. Classifying movement behaviour in relation to environmental conditions using hidden Markov models. Journal of Animal Ecology 78:1113-1123.

Pepperell, J., and T. Davis. 1999. Post-release behaviour of Black Marlin, Makaira indica, caught off the Great Barrier Reef with sportfishing gear. Marine Biology 135:369-380.

R Core Team. 2019. R: a language and environment for statistical compujting, Vienna, Austria. URL http://www.R-project.org/.

Rudershausen, P., W. Mitchell, J. Buckel, E. Williams, and E. Hazen. 2010. Developing a twostep fishery-independent design to estimate the relative abundance of deepwater reef fish: application to a marine protected area off the southeastern United States coast. Fisheries Research 105:254-260.

Rudershausen, P. J., B. J. Runde, and J. A. Buckel. 2020. Effectiveness of Venting and Descender Devices at Increasing Rates of Postrelease Survival of Black Sea Bass. North American Journal of Fisheries Management 40:125-132.

Runde, B. J., and J. A. Buckel. 2018. Descender devices are promising tools for increasing survival in deepwater groupers. Marine and Coastal Fisheries 10:100-117.

Runde, B. J., J. E. Harris, and J. A. Buckel. 2018. Symposium review: using electronic tags to estimate vital rates in fishes. Fisheries 43:268-270.

Runde, B. J., P. J. Rudershausen, B. Sauls, C. S. Mikles, and J. A. Buckel. 2019. Low discard survival of Gray Triggerfish in the southeastern US hook-and-line fishery. Fisheries Research 219:105313.

SAFMC. 2016. Snapper Grouper Fishery Management Plan. South Atlantic Fishery Management Council.

This article is protected by copyright. All rights reserved 
Seber, G. A. F. 1982. The estimation of animal abundance and related parameters, Volume 8. Blackburn press Caldwell, New Jersey.

Seitz, A. C., M. B. Courtney, M. D. Evans, and K. Manishin. 2019. Pop-up satellite archival tags reveal evidence of intense predation on large immature Chinook Salmon (Oncorhynchus tshawytscha) in the North Pacific Ocean. Canadian Journal of Fisheries and Aquatic Sciences:1-8.

Theberge, S., and S. J. Parker. 2005. Release methods for rockfish. Sea Grant Oregon, Oregon State University.

Vermard, Y., E. Rivot, S. Mahévas, P. Marchal, and D. Gascuel. 2010. Identifying fishing trip behaviour and estimating fishing effort from VMS data using Bayesian Hidden Markov Models. Ecological Modelling 221:1757-1769.

Viana, M., L. McNally, N. Graham, D. G. Reid, and A. L. Jackson. 2013. Ignoring discards biases the assessment of fisheries' ecological fingerprint. Biology Letters 9:20130812.

Wetherbee, B. M., and E. Cortés. 2004. Food consumption and feeding habits. Pages 232-253 in Biology of Sharks and their Relatives. CRC press.

Wilson, A. D., M. Wikelski, R. P. Wilson, and S. J. Cooke. 2015. Utility of biological sensor tags in animal conservation. Conservation Biology 29:1065-1075.

Yergey, M. E., T. M. Grothues, K. W. Able, C. Crawford, and K. DeCristofer. 2012. Evaluating discard mortality of Summer Flounder (Paralichthys dentatus) in the commercial trawl fishery: developing acoustic telemetry techniques. Fisheries Research 115:7281.Zucchini, W., I. L. MacDonald, and R. Langrock. 2016. Hidden Markov models for time series: an introduction using R. Chapman and Hall/CRC.

Zucchini, W., I. L. MacDonald, and R. Langrock. 2016. Hidden Markov models for time series: an introduction using R. Chapman and Hall/CRC.

This article is protected by copyright. All rights reserved 
Tables and Figures

Table 1. Information for individual groupers off North Carolina, USA. "Site" identifies whether the fish were tagged at the shelf break ("Shelf") or at the Snowy Wreck ("Wreck"). Tag names are comprised of the species and a unique identifying number. Tag names including "tag 1" or "tag 2" identify individuals that were double-tagged. Fish were either released alive with a descender device ("Descend"), descended after sacrifice ("Descend dead"), or released into a bottomless surface enclosure where they either swam down ("Surface cage, swam") or floated ("Surface cage, floated"). "Survival, full" indicates that the fish was still alive at the end of the study period. Fates were determined mainly by hidden Markov model (HMM); "Analysis 1 fate" indicates the assigned fate when the HMM results were interpreted more strictly (i.e., lower subjectivity). "Analysis 2 fate" indicates the assigned fate when we altered fates subjectively and are only present in this table when they differed from those in Analysis 1. Days alive were used as inputs for two Kaplan-Meier survivorship procedures.

\begin{tabular}{|c|c|c|c|c|c|c|c|c|}
\hline & & $\begin{array}{l}\text { Total } \\
\text { length }\end{array}$ & $\begin{array}{r}\text { Capture } \\
\text { depth }\end{array}$ & & Analysis 1 & Days & Analysis 2 & Days \\
\hline Site & Tag name & $(\mathrm{mm})$ & $(\mathrm{m})$ & Release type & Fate & alive & Fate & alive \\
\hline Shelf & Gag 1 & 1085 & 72 & Descend & Mortality & 0 & & \\
\hline Shelf & Red Grouper 1 & 850 & 116 & Descend & Survival, full & 123 & & \\
\hline Shelf & Scamp 1 & 675 & 85 & Descend & Mortality & 3 & & \\
\hline Shelf & Scamp 2 & 630 & 85 & Descend & Mortality & 0 & & \\
\hline Shelf & Scamp 3 & 680 & 85 & Descend dead & - & & & \\
\hline Shelf & Scamp 4 & 610 & 76 & Descend & Survival, full & 124 & & \\
\hline Shelf & Scamp 5 & 510 & 82 & Surface cage, swam & Mortality & 0 & Emigration & 0 \\
\hline Shelf & Scamp 6 & 650 & 88 & Descend & Mortality & 4 & & \\
\hline Shelf & Scamp 7 & 595 & 116 & Descend & Mortality & 0 & Mortality & 7 \\
\hline Shelf & Scamp 8 & 550 & 117 & Descend & Mortality & 0 & Mortality & 7 \\
\hline Shelf & Scamp 9 & 520 & 91 & Descend & Survival, full & 34 & & \\
\hline Shelf & Scamp 10 & 490 & 66 & Descend & Tag loss & 6 & & \\
\hline Shelf & Scamp 11 & 680 & 85 & Surface cage, floated & Mortality & 0 & & \\
\hline Shelf & Snowy Grouper 1 & 555 & 119 & Descend & Mortality & 0 & Emigration & 0 \\
\hline
\end{tabular}




\begin{tabular}{|c|c|c|c|c|c|c|c|c|}
\hline Shelf & Snowy Grouper 2 & 410 & 119 & Descend & Mortality & 0 & & \\
\hline Shelf & Snowy Grouper 3 & 415 & 91 & Descend & Mortality & 2 & & \\
\hline Shelf & Snowy Grouper 4 & 430 & 79 & Descend & $\begin{array}{l}\text { Survival, tag } \\
\text { loss }\end{array}$ & 9 & & \\
\hline Shelf & Snowy Grouper 5 & 390 & 118 & Descend dead & - & & & \\
\hline Shelf & Snowy Grouper 6 & 600 & 95 & Descend & Survival, full & 119 & & \\
\hline Shelf & Snowy Grouper 7 & 470 & 115 & Descend & Mortality & 3 & & \\
\hline Shelf & Snowy Grouper 8 & 560 & 120 & Descend & Survival, full & 63 & & \\
\hline Shelf & Snowy Grouper 9 & 430 & 80 & Descend & Mortality & 1 & Tag loss & 16 \\
\hline Shelf & Snowy Grouper 10 & 420 & 119 & Descend & Survival, full & 63 & & \\
\hline Shelf & Snowy Grouper 11 & 365 & 117 & Descend dead & - & & & \\
\hline Shelf & Snowy Grouper 12 & 385 & 117 & Descend & Survival, full & 63 & & \\
\hline Shelf & Snowy Grouper 13 & 395 & 117 & Descend & Survival, full & 63 & & \\
\hline Shelf & Snowy Grouper 14 & 365 & 117 & Descend & Survival, full & 63 & & \\
\hline Shelf & Snowy Grouper 15 & 460 & 82 & Descend & Survival, full & 63 & & \\
\hline Shelf & Snowy Grouper 16 & 410 & 91 & Descend & Survival, full & 63 & & \\
\hline Shelf & Snowy Grouper 17 & 420 & 108 & Descend & Mortality & 0 & Emigration & 11 \\
\hline Shelf & Snowy Grouper 18 & 390 & 99 & Descend & Survival, full & 34 & & \\
\hline Shelf & Snowy Grouper 19 & 590 & 116 & Descend & Emigration & 1 & & \\
\hline Shelf & Snowy Grouper 20 & 855 & 113 & Descend & Mortality & 0 & Emigration & 11 \\
\hline Shelf & Snowy Grouper 21 tag 1 & 645 & 116 & Descend & Mortality & 0 & Emigration & 2 \\
\hline Shelf & Snowy Grouper 21 tag 2 & 645 & 116 & Descend & Mortality & 0 & Emigration & 2 \\
\hline Shelf & Snowy Grouper 22 & 710 & 116 & Surface cage, swam & Mortality & 0 & Emigration & 5 \\
\hline Shelf & Snowy Grouper 23 tag 1 & 870 & 116 & Descend & Mortality & 0 & Emigration & 4 \\
\hline Shelf & Snowy Grouper 23 tag 2 & 870 & 116 & Descend & Mortality & 0 & Tag loss & 0 \\
\hline Shelf & Snowy Grouper 24 & 450 & 113 & Descend & Mortality & 3 & & \\
\hline Shelf & Snowy Grouper 25 tag 1 & 740 & 116 & Descend & Mortality & 0 & Emigration & 0 \\
\hline Shelf & Snowy Grouper 25 tag 2 & 740 & 116 & Descend & Mortality & 0 & Emigration & 0 \\
\hline Shelf & Snowy Grouper 26 & 440 & 119 & Surface cage, floated & Mortality & 0 & & \\
\hline Shelf & Snowy Grouper 27 & 370 & 116 & Surface cage, floated & Mortality & 0 & & \\
\hline Shelf & Snowy Grouper 28 & 725 & 116 & Surface cage, floated & Mortality & 0 & & \\
\hline
\end{tabular}




\begin{tabular}{|c|c|c|c|c|c|c|c|c|}
\hline Shelf & Snowy Grouper 29 & 900 & 116 & Surface cage, floated & Mortality & 0 & & \\
\hline Shelf & Snowy Grouper 30 & 655 & 116 & Surface cage, floated & Mortality & 0 & & \\
\hline Shelf & Snowy Grouper 31 & 390 & 118 & Surface cage, floated & Mortality & 0 & & \\
\hline Shelf & Speckled Hind 1 & 770 & 119 & Descend & Mortality & 0 & & \\
\hline Shelf & Speckled Hind 2 & 645 & 117 & Descend & Survival, full & 63 & & \\
\hline Shelf & Speckled Hind 3 & 540 & 90 & Descend & Tag loss & 34 & & \\
\hline Shelf & Speckled Hind 4 & 570 & 116 & Descend & Mortality & 3 & & \\
\hline Shelf & Yellowmouth Grouper 1 tag 1 & 730 & 87 & Descend & Mortality & 1 & & \\
\hline Shelf & Yellowmouth Grouper 1 tag 2 & 730 & 87 & Descend & Mortality & 1 & & \\
\hline Shelf & Yellowmouth Grouper 2 & 620 & 113 & Descend & Mortality & 0 & & \\
\hline Shelf & Yellowmouth Grouper 3 & 595 & 113 & Descend & Mortality & 0 & & \\
\hline Shelf & Yellowmouth Grouper 4 & 570 & 119 & Descend & Survival, full & 64 & & \\
\hline Wreck & Snowy Grouper 1 wreck & 800 & 244 & Descend & Mortality & 0 & Emigration & 6 \\
\hline Wreck & Snowy Grouper 2 wreck & 920 & 244 & Descend & Mortality & 0 & Emigration & 0 \\
\hline Wreck & Snowy Grouper 3 wreck & 850 & 244 & Descend & Mortality & 0 & Emigration & 1 \\
\hline Wreck & Snowy Grouper 4 wreck & 800 & 244 & Descend & Mortality & 0 & Emigration & 9 \\
\hline Wreck & Snowy Grouper 5 wreck & 1020 & 244 & Descend & Mortality & 0 & Emigration & 2 \\
\hline
\end{tabular}


Table 2. Parameter estimates for our 3-state hidden Markov models. The three data streams parameterized were mean acceleration (“Acc"), mean depth relative to the depth of release ("RelDepth"), and standard deviation of all depth values in each time bin ("DepthSD”). For each data stream, "SD" refers to the standard deviation parameter. "Zmass" refers to the zero-mass parameter which was estimated for Acc and DepthSD.

\begin{tabular}{lrrr}
\hline & State 1 & State 2 & State 3 \\
\hline Acc Mean & 0.386 & 0.420 & 0.574 \\
Acc SD & 0.405 & 0.428 & 0.498 \\
Acc Zmass & 4.30 E-05 & 9.99 E-09 & 4.56 E-04 \\
RelDepth Mean & 1.019 & 1.105 & 0.815 \\
RelDepth SD & 0.022 & 0.087 & 0.339 \\
DepthSD Mean & 0.543 & 1.462 & 5.173 \\
DepthSD SD & 0.310 & 1.240 & 5.605 \\
DepthSD Zmass & 0.472 & 0.249 & 0.104 \\
\hline
\end{tabular}

This article is protected by copyright. All rights reserved 


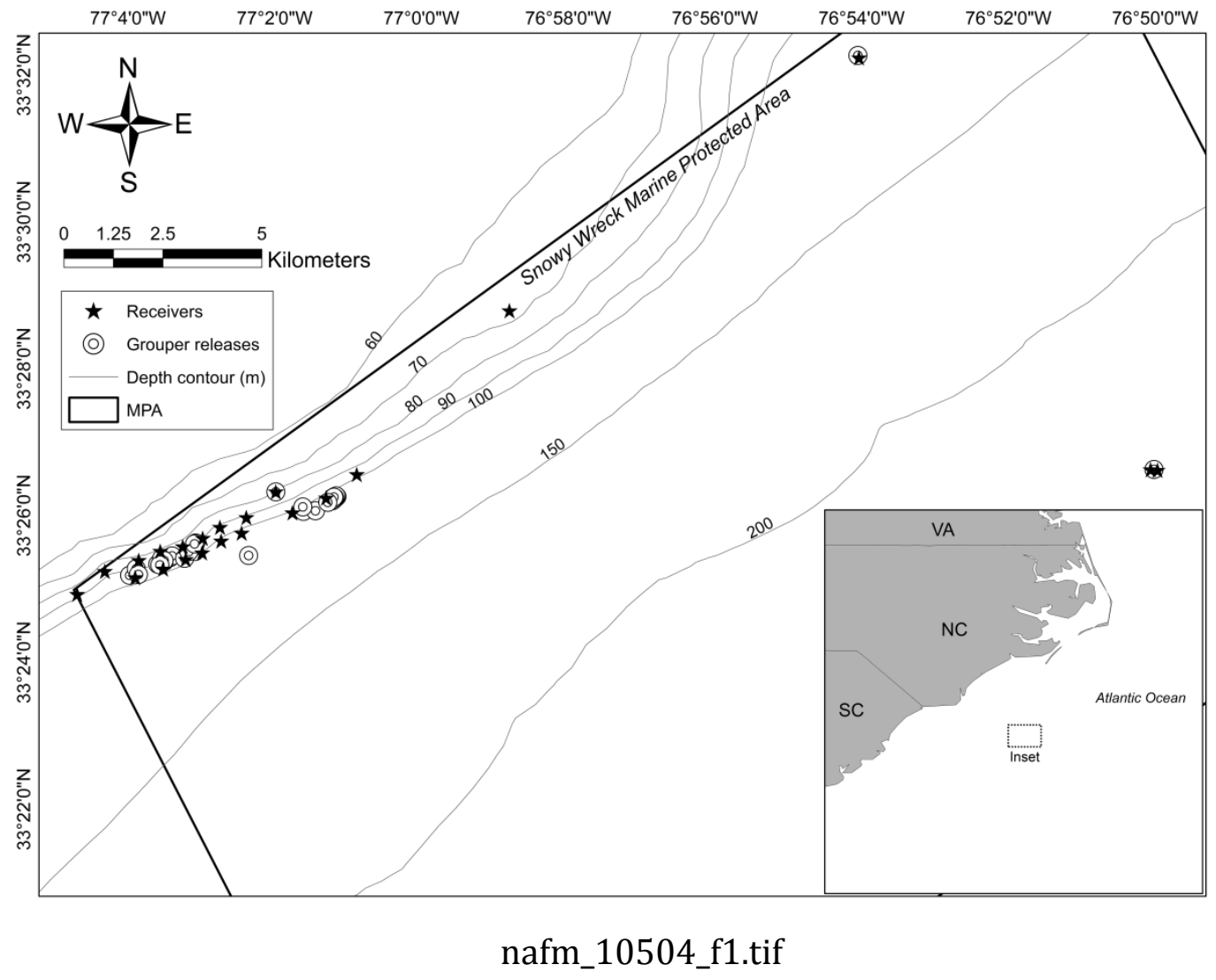

This article is protected by copyright. All rights reserved 

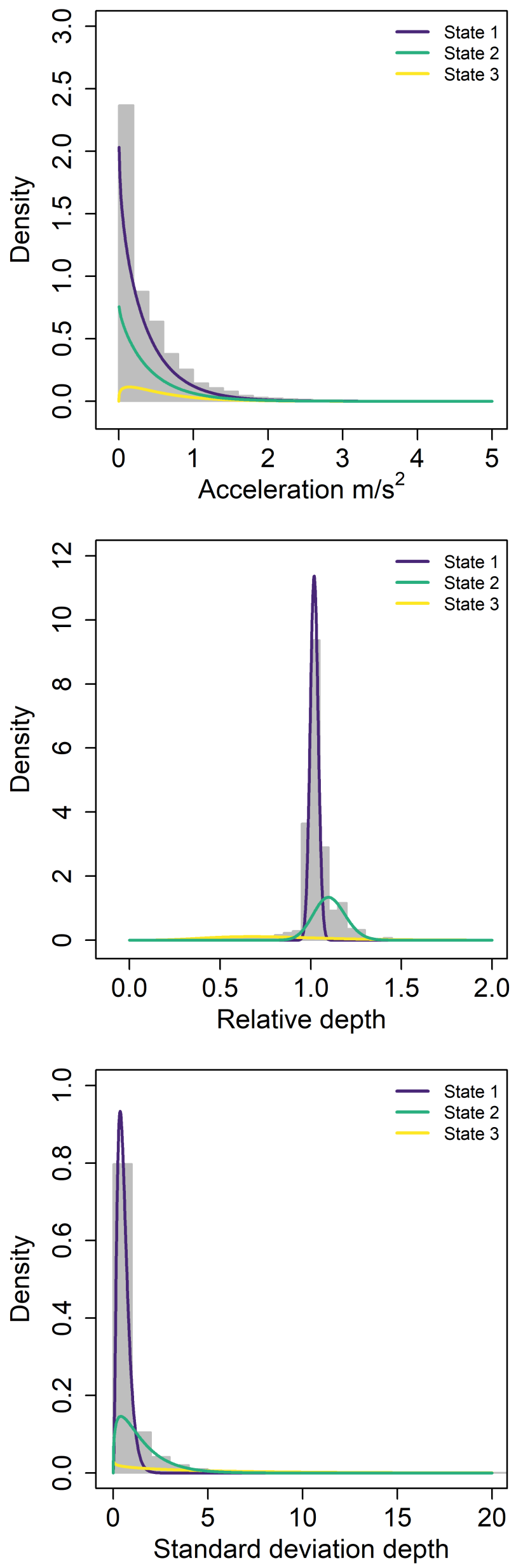

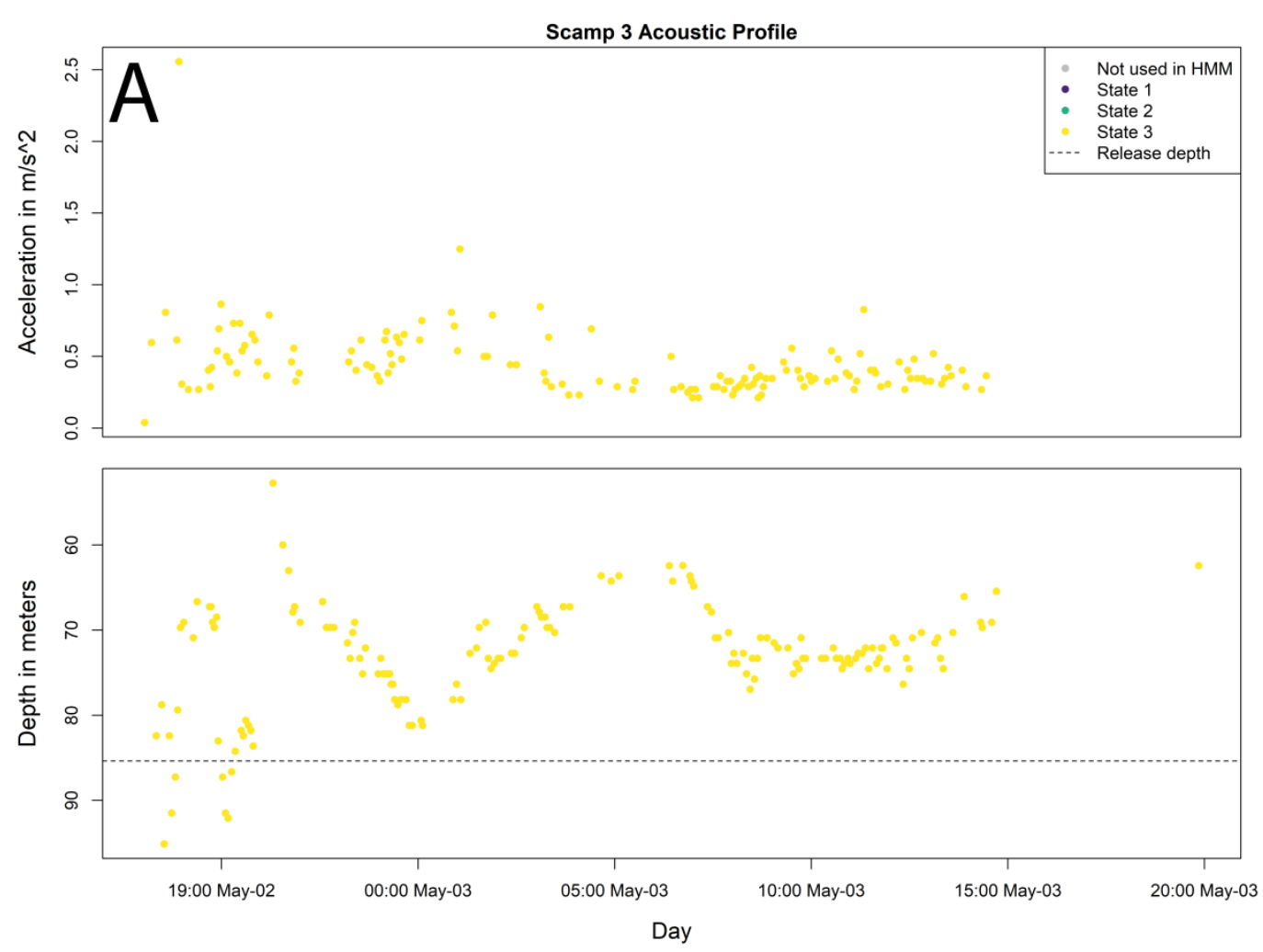

nafm_10504_f3a.tif

This article is protected by copyright. All rights reserved 

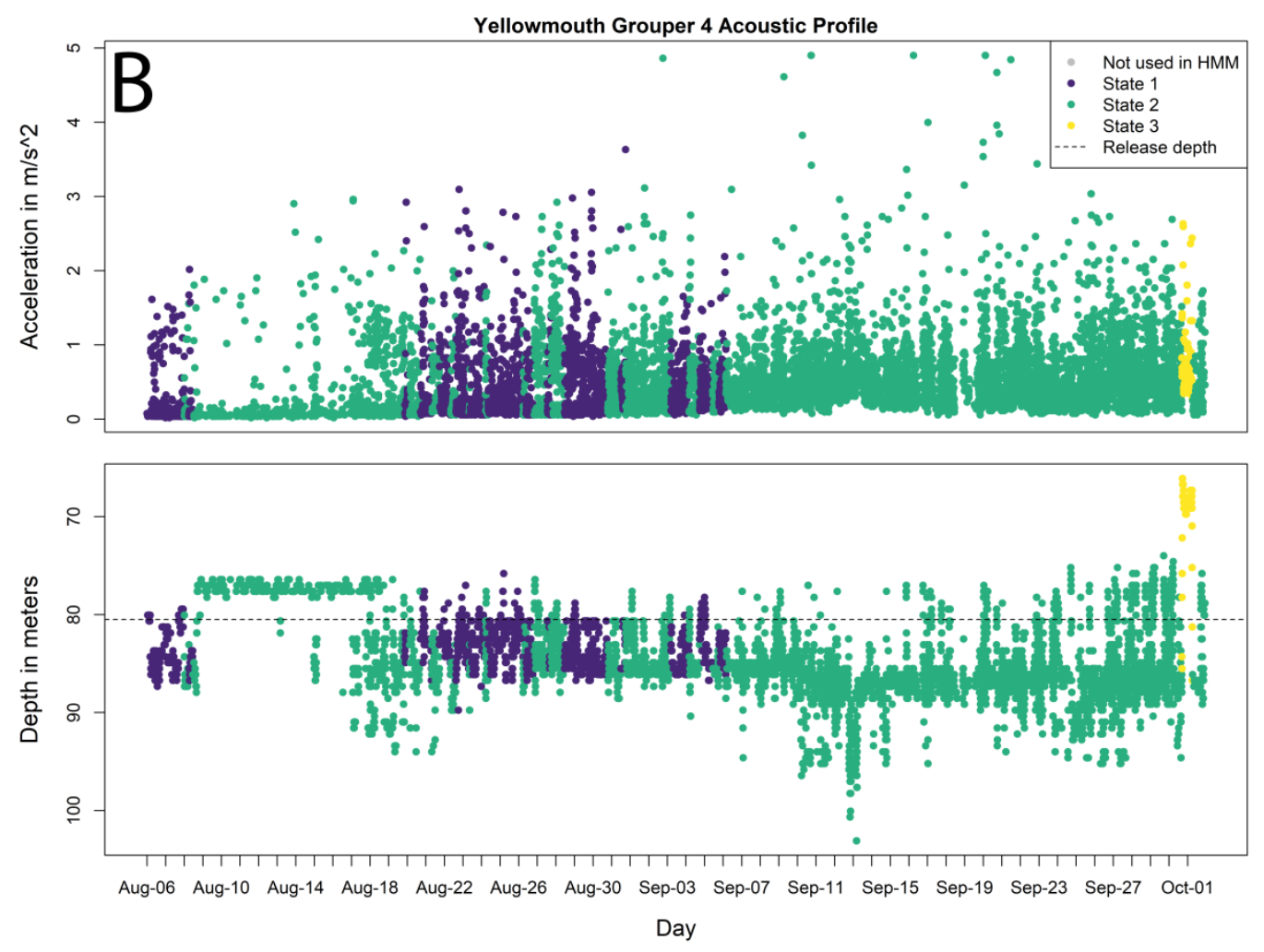

nafm_10504_f3b.tif

This article is protected by copyright. All rights reserved 

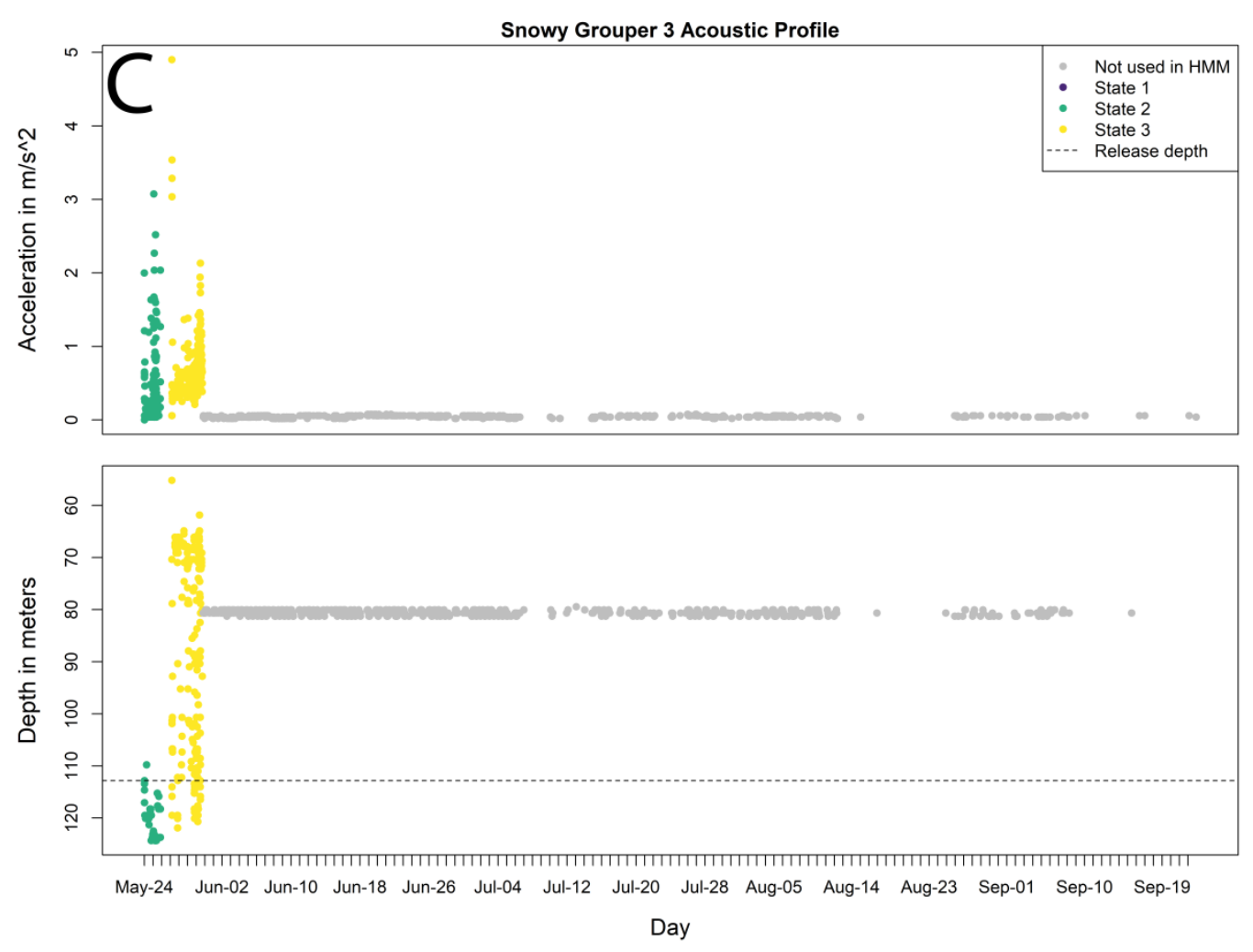

nafm_10504_f3c.tif 

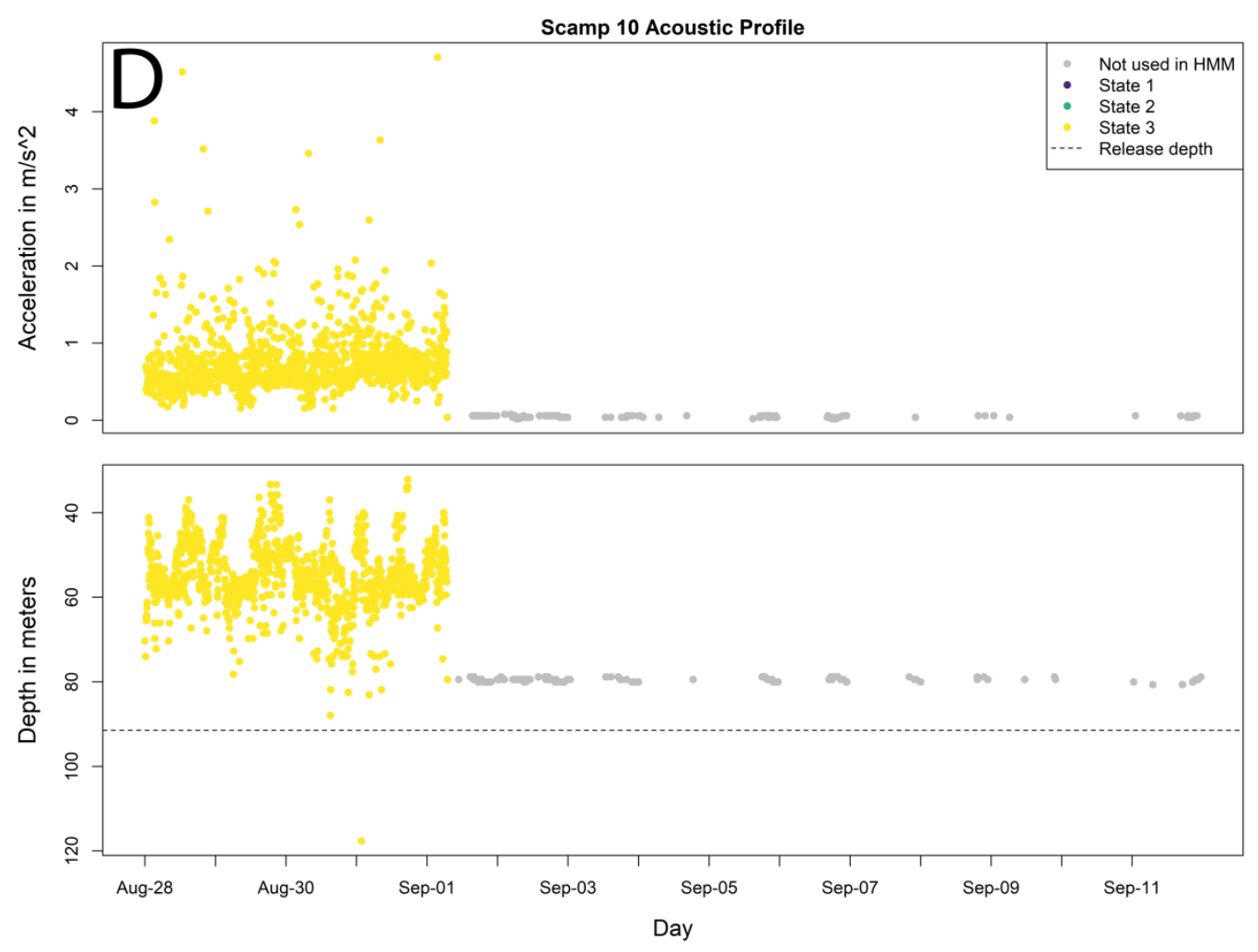

nafm_10504_f3d.tif 

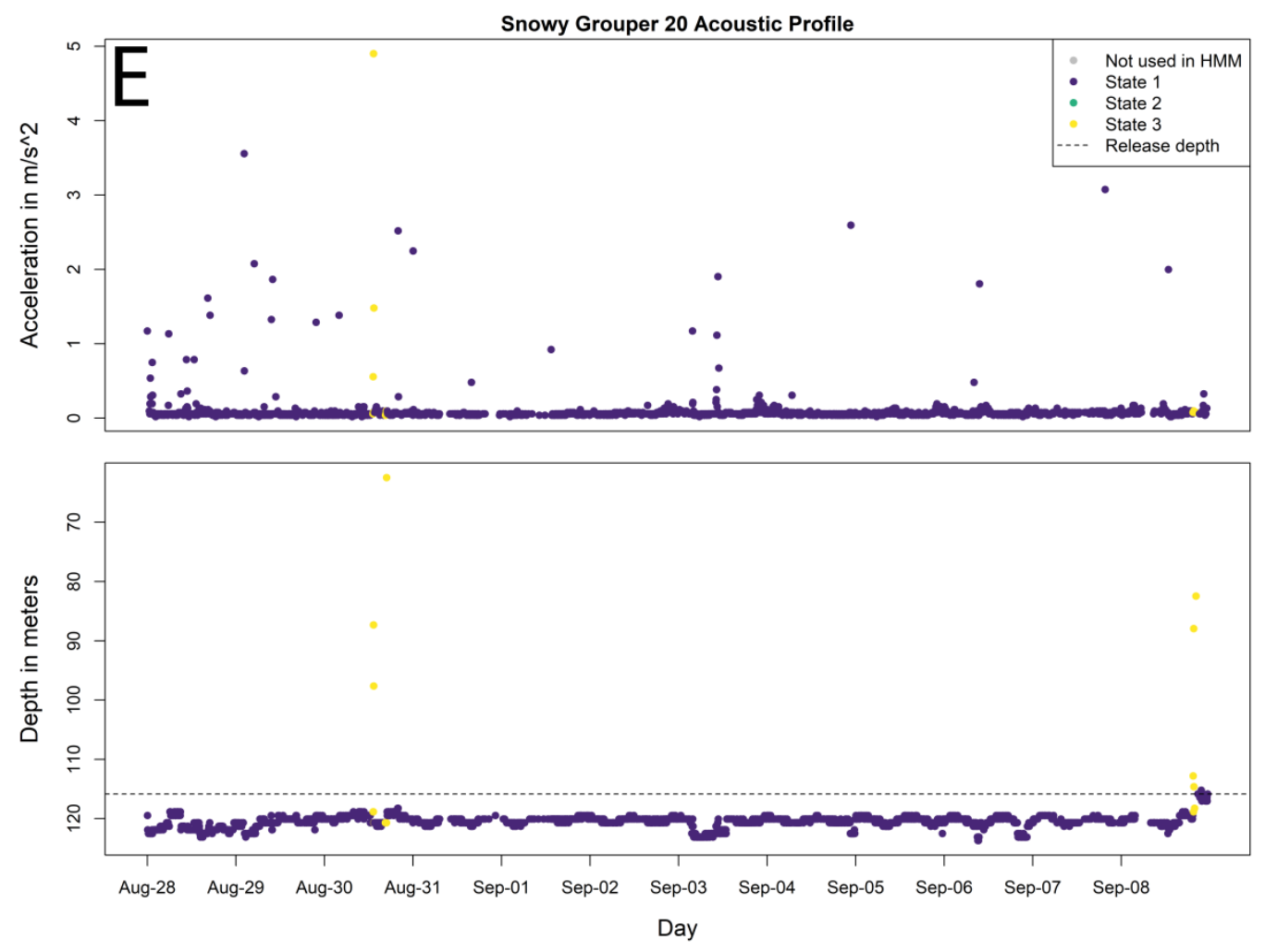

nafm_10504_f3e.tif

This article is protected by copyright. All rights reserved 

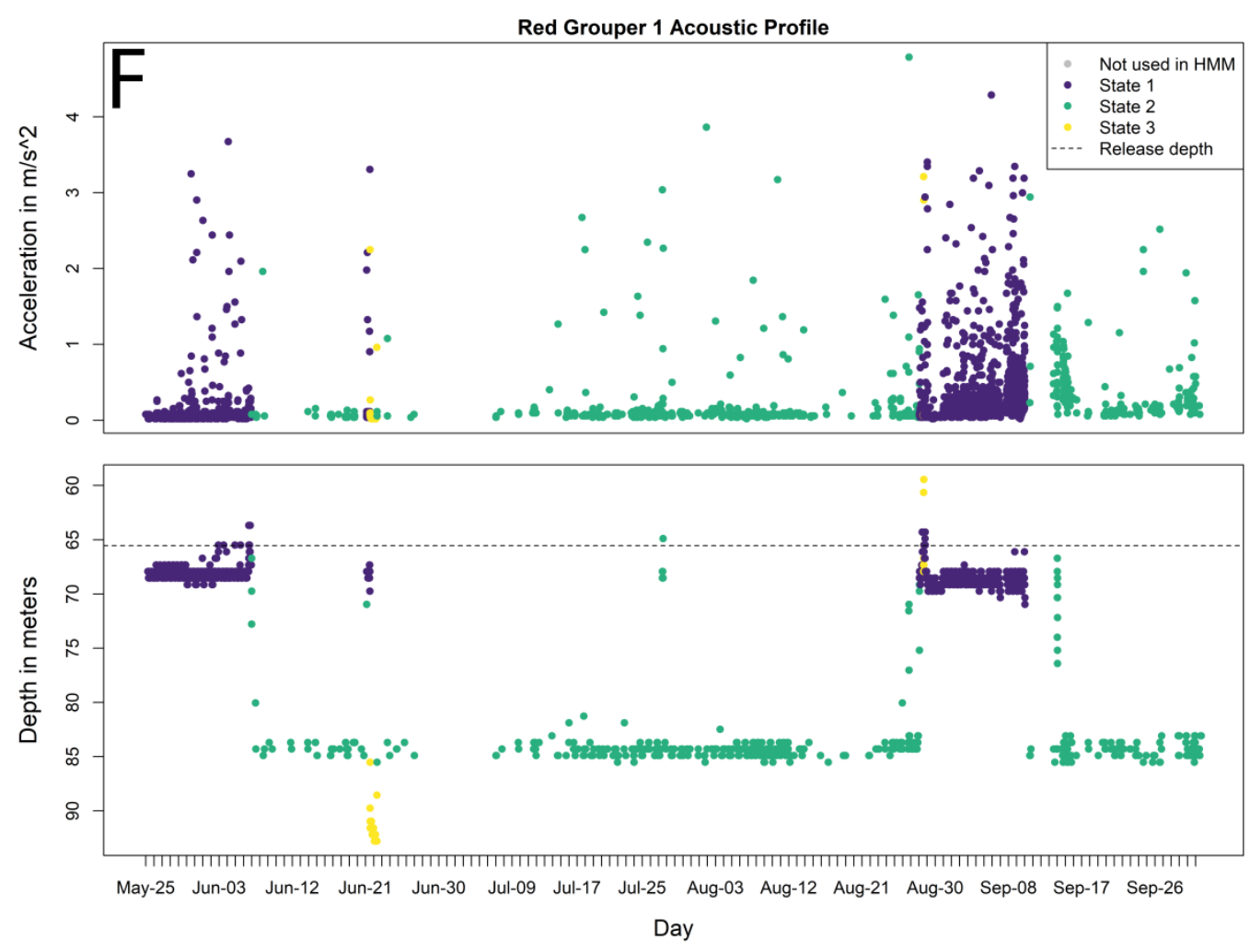

nafm_10504_f3f.tif 


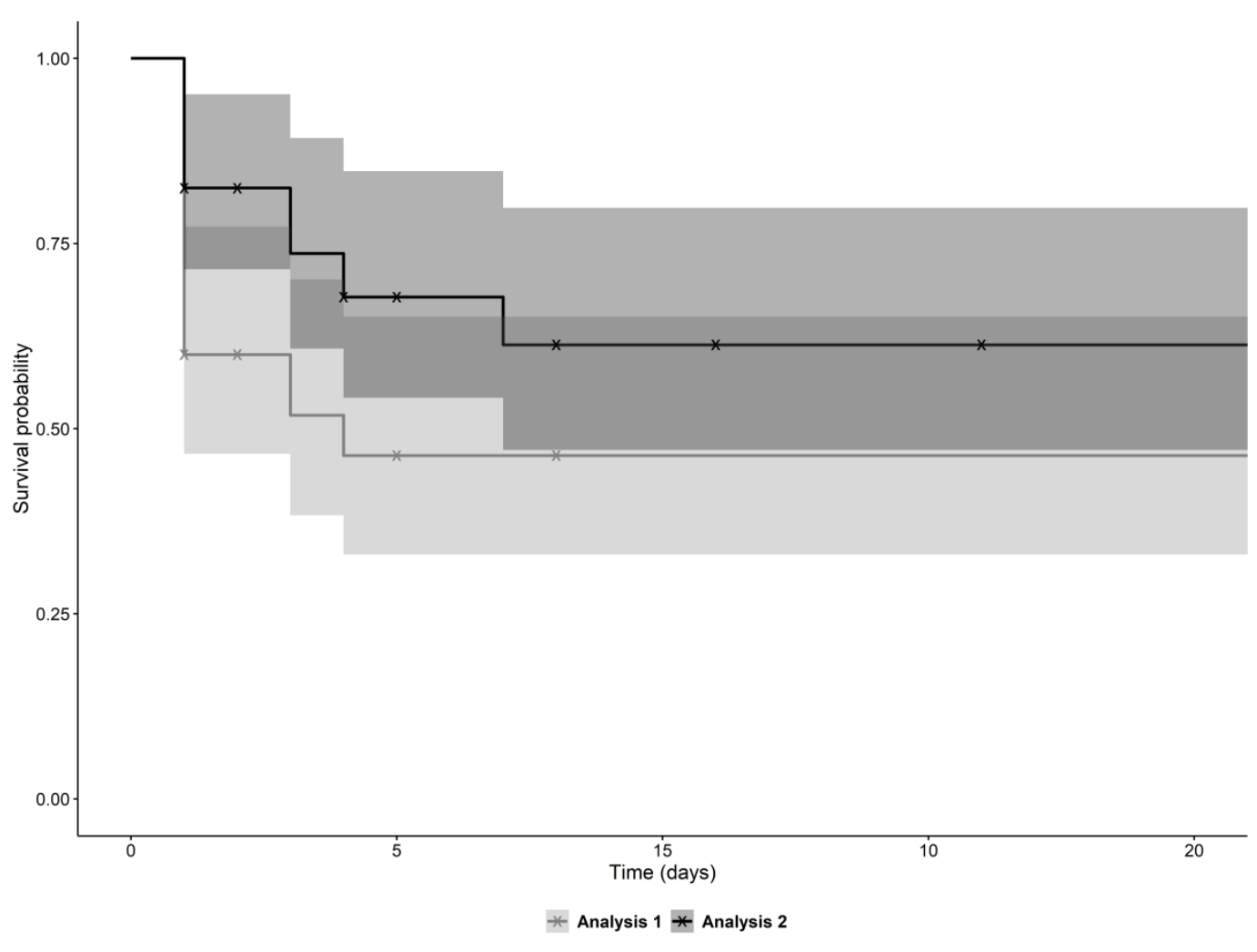

nafm_10504_f4.tif 